\title{
Forecasting Prices in Regime-Switching Markets
}

\author{
Luis E. Pereiro* \\ and \\ Martín González-Rozada**
}

\begin{abstract}
Linear autoregressive (LAR) models poorly predict asset prices in nonlinear, regimeswitching markets. We introduce SETAR, a threshold model that accounts for nonlinearities, to test for the existence of regime-switching in global equity markets. A comparison of SETAR's predictive power against that of LAR models suggests that SETAR yields more accurate long forecasts, in both emerging and developed stock markets. We discuss extensions of threshold models into portfolio management, corporate valuation, and the long-term forecasting of financial indicators.
\end{abstract}

\footnotetext{
* Luis E. Pereiro is Professor of International Finance at the Business School, Universidad Torcuato Di Tella. Address: Sáenz Valiente 1010, C1428BIJ, Buenos Aires, Argentina. E-mail: lpereiro@utdt.edu

** Martín González-Rozada is Professor of Econometrics at the Economics Department, Universidad Torcuato Di Tella. Address: Sáenz Valiente 1010, C1428BIJ, Buenos Aires, Argentina. E-mail: mrozada@utdt.edu
} 


\section{The Predicament of Regime-Switching}

Expected future prices are crucial inputs to asset selection and allocation. But certain asset prices are particularly difficult to forecast due to nonlinearities called regime switches. A regime-switching price suffers, from time to time, from discrete, sharp dislocations, jumping from one state or regime to a widely different one-and back. The shift is triggered by a radical change, called break, in the process that underlies price formation. In bonds, or commodities like gold, sudden changes in investor sentiment may produce dramatic shifts in mean prices to be followed, after some period, by retrogression to a previous regime. In individual stocks, a large, persistent price deviation may result as a consequence of a merger or acquisition event, the entry or exit of a formidable competitor, an R\&D breakthrough, or a flopped reorganization. And in stock markets, average price indexes may shift due to major political or economic crises, banking failures, expropriations, hyperinflation, the stock market's integration to or detachment from the global financial system, or any other turn of events that drastically alters a stock market's dynamical behavior.

Linear autoregressive (LAR) models badly fit regime-switching time series: their predictive power is easily spoiled by the nonlinearities embodied in regime shifts. ${ }^{1}$ To negotiate this hurdle, analysts preserve the linearity assumption by carefully selecting the data they use; for example, they subjectively identify the latest 'rupture' in the pricegenerating process-say, a major slump-and proceed to forecast a long-term price by using a LAR model that is fed only with the data available since the crisis. This approach is seriously flawed, however, for it produces forecasts based on a subset of past data that 
is not truly representative of a future which, in all likelihood, will include regime switches.

We introduce SETAR, one in a broad family of univariate forecasting models that truly account for nonlinearities. In essence, SETAR econometrically identifies different price regimes and is thus able to produce composite forecasts that take into account the probabilities of the price being in those regimes. The advantage of this modeling strategy is that it tends to yield more precise forecasts. In this article, we use SETAR to test for the existence of price shifts in global equity markets and show that, for most cases, SETAR has better predictive power than LAR formulations. ${ }^{2}$

\section{Identifying Regime-Switching Stock Markets}

Emerging stock markets come naturally to mind when one thinks of regimeswitching. Goetzmann and Jorion's [1999] have shown that a number of markets emerge when dramatic changes in political, economic and institutional conditions make them suddenly attractive to international investors; they submerge when, hit by a major crisis, disappear from the radar screen of investors for months-or even years; and reemerge when a sweeping economic change in the opposite direction makes them enticing, once again, to the international investment community. Technically speaking, such markets regularly switch from an upper (emergence, or expansionary) regime to a lower (submergence, or recessionary) regime, and back-thus suggesting a two-state regime-switching behavior. 
One way to econometrically check for the existence of price shifts is the self-exciting threshold autoregressive model, or SETAR, developed by Tong [1983]. 'Self-exciting' means forecasts are inherently defined by the historical behavior of the time series. Put differently, regimes are not subjectively defined by the analyst but are instead patterned after the actual, observed data. SETAR decomposes the nonlinear behavior of a stock price index into two or more linear regimes separated by thresholds-values of the index which constitute the borders between regimes. Once thresholds are computed, it is easy to identify the crossover dates - the points in time at which the price index crosses the thresholds.

In Exhibit 1A, we check for the existence of regime-switching in a sample of twentytwo emerging stock markets. More specifically, we examine whether a market is a tworegime system by using a SETAR model of order $1-$ a nonlinear autoregressive model described by the following equation:

$$
\mathrm{X}_{\mathrm{t}}=\mu_{1} \mathrm{I}\left(\mathrm{X}_{\mathrm{t}-1}>\mathrm{r}\right)+\mu_{2} \mathrm{I}\left(\mathrm{X}_{\mathrm{t}-1} \leq \mathrm{r}\right)+\left[\alpha_{1} \mathrm{I}\left(\mathrm{X}_{\mathrm{t}-1}>\mathrm{r}\right)+\alpha_{2} \mathrm{I}\left(\mathrm{X}_{\mathrm{t}-1} \leq \mathrm{r}\right)\right] \mathrm{X}_{\mathrm{t}-1}+\mathrm{u}_{\mathrm{t}}
$$

where $X_{t}$ represents the stock market index; $\mu_{1}$ and $\mu_{2}$ are the intercepts; $\alpha_{1}$ and $\alpha_{2}$ are the regression coefficients; $r$ is the threshold value that separates the lower form the upper regime; $I$ is an indicator function which signals whether the market index is in the upper or the lower regime; and $u_{t}$ is the error term. ${ }^{3}$

SETAR selects the threshold so that the likelihood of a change in the behavior of the series is maximized, and thresholds are thus detected at a specific level of significance: if 
the $t$-statistic of the threshold is above a critical value, we have detected one threshold, and therefore, two different price regimes, with strong statistical significance. Markets with $t$-statistics below critical values cannot be characterized as regime-switching systems, and may be modeled instead by using LAR formulations. 4

To construct Exhibit 1A we use monthly data coming from Datastream, starting at the earliest available date. Since regime-switching forecasting requires long data series to properly capture price shifts, we fully utilize all information available for each country; hence the uneven lengths of the series. All indexes are based in US\$, and 'Horizon' is the length of the period analyzed for each market. 'Threshold Index Value' is the value at which the market index crosses from one regime to the other. The symbol ${ }^{* * *}$ means the threshold is significant at $1 \%$ ( $t$-critical: 10.18$)$; and ${ }^{* *}$, significant at $5 \%$ ( $t$-critical: 7.52). Critical values are from González-Rozada and Gonzalo [1997].

As Exhibit 1A shows, price thresholds turn out to be statistically significant in 15 out of the 22 emerging markets, or $68 \%$ of the sample. Since stock prices could, in principle, display more than two regimes, every time we find one threshold (and consequently, two regimes) we repeat the search process within each of the detected regimes until we find no additional thresholds. Using this procedure, we conclude that all emerging regime-switching markets show but a single threshold-namely, they all behave as two-regime systems. Exhibit 1A documents also the crossover dates at which indexes cross their respective thresholds. 
Exhibit 1.

Identifying Regime-Switching Stock Markets

Panel A: Emerging Markets

\begin{tabular}{|c|c|c|c|c|c|c|c|}
\hline Market & Index & Period & $\begin{array}{c}\text { Horizon } \\
\text { (years) }\end{array}$ & $\begin{array}{l}\text { hreshold } \\
\text { index } \\
\text { value } \\
\end{array}$ & Crossover dates & $t$-Statistic & $\begin{array}{c}\text { Regime } \\
\text { Switching? }\end{array}$ \\
\hline Argentina & Merval & Jan 88 - Mar 09 & 21.3 & 589.1 & $\begin{array}{l}\text { Aug-91, Jul-92, Jan-94, Mar-94, May-94, Jun-94, } \\
\text { Aug-94, Oct-94, May-96, Jul-96, Nov-96, Jun-9 8, } \\
\text { Feb-oo, Mar-0o, Apr-06, Nov-06, Aug-0 8 }\end{array}$ & $27.84^{* * *}$ & Yes \\
\hline Brazil & IBOV & Dec 89 - Mar o9 & $19 \cdot 3$ & $16,816.3$ & - & 2.93 & No \\
\hline Chile & IPSA & Jan 89- Mar o9 & 20.3 & 3.6 & - & $4 \cdot 31$ & No \\
\hline China & SZBSHR & Oct 92 - Mar o9 & 16.5 & 40.0 & Mar-01, Jul-01, Sep-o6, Oct-o8, Mar-o9 & $8.55^{* *}$ & Yes \\
\hline Hong Kong & HIS & Jan 88 - Mar o9 & 21.3 & $2,044.1$ & - & 6.40 & No \\
\hline India & Sensex & Jan 88 - Mar o9 & 21.3 & 104.7 & - & $3 \cdot 51$ & No \\
\hline Indonesia & JCI & Jan 88 - Mar o9 & 21.3 & 0.3 & Aug-89, Oct-89, Feb-9o, Oct-9o, Dec-93, Mar-94 & $23.69^{* * *}$ & Yes \\
\hline Korea & Kospi2 & Jan 90 - Mar 09 & 19.3 & 0.1 & $\begin{array}{l}\text { Jan-96, Jul-96, Nov-96, Aug-97, Jul-07, Aug-07 } \\
\text { Sep-07, Apr-o8, May-08, Aug-08 }\end{array}$ & $4 \cdot 38$ & No \\
\hline Malaysia & KLCI & Jan 88 - Mar o9 & 21.3 & 396.1 & $\begin{array}{l}\text { Dec-93, Mar-94, Aug-94, Dec-94, May-95, Oct-95, } \\
\text { Jan-96, Jul-97, Nov-0o, Dec-oo, May-07, Jun-07, } \\
\text { Jul-07, Aug-07, Oct-07, Mar-o8, Apr-08, May-o } 8\end{array}$ & $121.14^{* *}$ & Yes \\
\hline Mexico & Mexbol & Jan 88 - Mar o9 & 21.3 & $1,533.7$ & - & 4.93 & No \\
\hline Pakistan & KSE & Mar 98 - Mar o9 & 11.1 & 122.9 & $\begin{array}{l}\text { Feb-o6, May-o6, Oct-06, Nov-06, Jan-07, Feb-07, } \\
\text { Mar-07, Jul-o8 }\end{array}$ & $11.47^{* * *}$ & Yes \\
\hline Peru & IGBVL & Aug 92 - Mar o9 & 16.7 & $2,247 \cdot 7$ & - & 4.43 & No \\
\hline Philippines & Pcomp & Nov 91 - Mar o9 & $17 \cdot 4$ & 99.1 & $\begin{array}{l}\text { Dec-93, Mar-94, Apr-94, Jan-95, May -95, Oct-95, } \\
\text { Dec-95, Jul-97 }\end{array}$ & $46.05^{* * *}$ & Yes \\
\hline Poland & CPTX & Jul 97 - Mar o9 & 11.8 & $2,195 \cdot 3$ & Apr-o6, May-o6, Jul-o6, Aug-o6, Oct-o6, Sep-o 8 & $11.51^{* * *}$ & Yes \\
\hline Russia & RTSI\$ & Sep 95-Mar o9 & 13.6 & $1,551.1$ & Apr-o6, May-o6, Aug-o6, Sep-o6, Oct-o6, Sep-o 8 & $15 \cdot 39^{* * *}$ & Yes \\
\hline Singapore & FSSTI & Aug 99 - Mar o9 & 9.7 & $1,210.1$ & $\begin{array}{l}\text { May-oo, Aug-oo, Sep-oo, Dec-04, Nov-08, Dec-08, } \\
\text { Jan-o 9, Apr-09 }\end{array}$ & $7.67^{* *}$ & Yes \\
\hline South Africa & JALSH & Jun 95 - Mar o9 & 13.8 & $3,159.6$ & Jan-o6, Feb-o6, Mar-o6, May-o6, Oct-o6, Sep-o 8 & $12.33^{* * *}$ & Yes \\
\hline Sri Lanka & CSEALL & Jan 88 - Mar o9 & 21.3 & 20.6 & $\begin{array}{l}\text { Jan-94, May-94, Aug-94, Dec-94, Aug-05, Dec-o5, } \\
\text { Jan-06, Jun-06, Jul-06, Sep-o } 8\end{array}$ & $29.33^{* * *}$ & Yes \\
\hline Thailand & SET & Jan 88 - Mar o9 & 21.3 & 38.4 & May -9o, Aug-9o, Sep-93, Oct-96 & $29.41^{* * *}$ & Yes \\
\hline Taiwan & TWSE & Jan 88 - Mar o9 & 21.3 & 186.0 & $\begin{array}{l}\text { Jul-8 8, Dec-8 8, Jan-89, Aug-9o, Mar-91, Aug-91, } \\
\text { Jan-92, Apr-92, Dec-93, Aug-95, Sep-95, Oct-95, } \\
\text { Dec-95, Jan-96, Apr-96, Jan-99, Feb-99, Oct-oo, } \\
\text { Jan-04, Apr-04, Dec-04, Aug-05, Dec-05, Sep-08, } \\
\text { May-0 } 9\end{array}$ & $15.20^{* * *}$ & Yes \\
\hline Turkey & XU100 & Jan 90 - Mar o9 & 19.3 & $9,512.3$ & $\begin{array}{l}\text { Apr-91, Jun-93, Jul-93, Aug-93, Feb-94, Apr-95, } \\
\text { Aug-95, Jan-97, Aug-08, Feb-99, Feb-01, Apr-01, } \\
\text { May-01, Jan-02, Feb-02, Oct-03 }\end{array}$ & $14.88^{* * *}$ & Yes \\
\hline \multirow[t]{2}{*}{ Venezuela } & IBVC & Dec 93 - Mar 09 & $15 \cdot 3$ & $17,346.4$ & $\begin{array}{l}\text { Jun-97, Nov-97, Jan-04, Feb-04, Oct-o6, Jan-0 8, } \\
\text { Apr-08, May-08, Jun-08, Oct-08, Feb-o } 9\end{array}$ & $23.59^{* * *}$ & Yes \\
\hline & & $\begin{array}{l}\text { Average } \\
\text { Median }\end{array}$ & $\begin{array}{l}18.0 \\
19.3\end{array}$ & & & & \\
\hline
\end{tabular}


Panel B: Developed Markets

\begin{tabular}{|c|c|c|c|c|c|c|c|}
\hline Market & Index & Period & $\begin{array}{c}\text { Horizon } \\
\text { (years) }\end{array}$ & $\begin{array}{l}\text { hreshold } \\
\text { Index } \\
\text { Value }\end{array}$ & Crossover dates & $t$-Statistic & $\begin{array}{c}\text { Regime } \\
\text { Switching? }\end{array}$ \\
\hline Australia & AS30 & Jan 88 - Mar o9 & 21.3 & $1,512.1$ & - & 5.59 & No \\
\hline Austria & ATX & Dec 88 - Mar o9 & 20.3 & $1,226.8$ & - & 4.97 & No \\
\hline Belgium & BEL2O & Jan 91 - Mar o9 & 18.3 & $2,726.3$ & - & 5.77 & No \\
\hline Canada & SPTSX & Jan 88 - Mar o9 & 21.3 & $7,695.0$ & - & 6.49 & No \\
\hline Denmark & KFX & Dec 89 - Mar o9 & 19.3 & 59.7 & - & 4.12 & No \\
\hline Finland & HEX & Jan 88 - Mar o9 & 21.3 & $11,252.2$ & $\begin{array}{l}\text { Nov-99, Jan-01, Mar-06, Jun-06, Aug-06, Sep-o6, } \\
\text { Oct-o6, Sep-o } 8\end{array}$ & $10.50^{* * *}$ & Yes \\
\hline France & $\mathrm{CAC}_{40}$ & Jan 88 - Mar o9 & 21.3 & $5,870.1$ & - & 6.89 & No \\
\hline Germany & DAX & Jan 88 - Mar 09 & 21.3 & $6,670.5$ & - & $5 \cdot 98$ & No \\
\hline Italy & MIBTEL & Dec 93 - Mar o9 & $15 \cdot 3$ & $32,561.6$ & - & 5.70 & No \\
\hline Japan & TPX500 & Jan 93 - Mar o9 & 16.3 & 11.6 & $\begin{array}{l}\text { May -93, Jun-93, Jul-93, Nov-93, Jan-94, Jan-95, } \\
\text { Mar-95, Jun-95, Jul-95, a ug-95, Dec-95, Feb-96, } \\
\text { Mar-96, Jul-96, Oct-9 9, Jul-oo, Aug-oo, Sep-oo, } \\
\text { Apr-o6, May-06, Feb-07, Apr-o7 }\end{array}$ & $23.26 * * *$ & Yes \\
\hline Netherlands & AEX & Jan 88 - Mar o9 & 21.3 & 591.5 & $\begin{array}{l}\text { May -9 8, Jun-9 8, Jul-9 8, Aug-9 8, Dec-98, Feb-99, } \\
\text { Apr-99, May-99, aug-99, Sep-99, Oct-99, Sep-oo, } \\
\text { Dec-00, Feb-01, Apr-o6, May-06, Aug-06, Sep-o } 8\end{array}$ & $12.10^{* * *}$ & Yes \\
\hline Norway & OSEBX & Dec 95 - Mar 09 & $13 \cdot 3$ & 61.9 & Apr-o6, Jun-o6, Jul-o6, Aug-o6, Nov-06, Sep-o 8 & $7.72^{* *}$ & Yes \\
\hline New Zealand & NZSE & Mar 92 - Mar o9 & 17.1 & 426.1 & $\begin{array}{l}\text { Dec-93, Mar-94, Apr-94, Jun-94, Jul-94, May-98, } \\
\text { Apr-99, May-99, May-03, Oct-o8, May-99 }\end{array}$ & $10.89 * * *$ & Yes \\
\hline Portugal & BVLX & Dec 88 - Mar o9 & 20.3 & 820.5 & Oct-92, Jan-93, Jun-93, Aug-93, Sep-93, Jan-94 & $22.62 * * *$ & Yes \\
\hline Spain & IBEX & Jan 88 - Mar o9 & 21.3 & $12,443 \cdot 9$ & - & 3.50 & No \\
\hline Sweden & SAX & Jan 88 - Mar o9 & 21.3 & 37.8 & - & 6.42 & No \\
\hline Switzerland & SMI & Jul 88 - Mar o9 & 20.8 & $4,976.4$ & - & 7.16 & No \\
\hline United Kingdom & FTSE10o & Jan 88 - Mar o9 & 21.3 & $10,118.0$ & 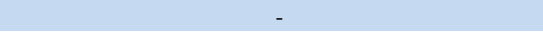 & 6.76 & No \\
\hline \multirow[t]{2}{*}{ United States } & SPX & Jan 88 - Mar o9 & 21.3 & $1,320.4$ & $\begin{array}{l}\text { Apr-99, May-99, Jun-9 9, Aug-9 9, Oct-99, Nov-oo, } \\
\text { Jan-01, Feb-01, Sep-o6, Jun-o8 }\end{array}$ & $17 \cdot 59^{* * *}$ & Yes \\
\hline & & $\begin{array}{l}\text { Average } \\
\text { Median }\end{array}$ & $\begin{array}{l}19.7 \\
21.3\end{array}$ & & & & \\
\hline
\end{tabular}

In Exhibit 1B we check for the presence of regime-switching in developed markets. To maintain consistency, data series here start at the earliest date that is available for emerging markets. While only $37 \%$ of the cases are effectively regime-switching, this category includes the largest stock market in the world-the U.S.'s. Again, all developed regime-switching markets display a single threshold.

The identification of a threshold in a stock market index is important: it signals to the analyst not only that stock price tends to shift its mean level, but also, that the index displays a different dynamical behavior above and below the threshold. By virtue of its dual structure, a threshold model is able to produce a composite price forecast that incorporates both dynamics, by using the probabilities of the index being in different states. As we discuss next, such capability has the potential to improve predictive power. 


\section{Forecasting Prices in Regime-Switching Markets}

The acid test of SETAR is whether it can produce more accurate forecasts than LAR models. Assume it is late June 2004, and an investor is pondering the future of global stock markets. The dot-com crash is over; $9 / 11$ is over; the S\&P 500 Index is at 1,141 , and market sentiment is up. The occurrence of a 'great recession' in the next several years is hardly fathomable. Yet the bankruptcy in April 2007 of New Century Financial, the largest subprime lender in the U.S., signaled the kickoff of one of the major stock market crises in recorded history. By late June 2009, for example, the S\&P500 Index was at $919-$ about $20 \%$ below its 2004 value.

Such a dramatic episode provides a strenuous testing ground, which we use to good effect in Exhibit 2 to compare the predictive power of LAR versus SETAR. The insample period covers from the start date of 'Period' as appearing in Exhibit 1 until June 30, 2004; whereas the forecasting period goes from June 30, 2004 until May 31, 2009. Some markets are missing in the exhibit since their in-sample data windows are too short to provide reliable results. We estimate several LAR models of different lag order, but show only the results of the best-fitting specification. As for SETAR, we use a forecasting equation that incorporates the probabilities of indexes being in the upstate and downstate regimes. 5 
Exhibit 2.

Predictive Ability of Linear Autoregressive (LAR) Models versus SETAR

Panel A: Emerging Markets

\begin{tabular}{|c|c|c|c|c|c|c|}
\hline Market & Model & $\begin{array}{c}\text { Probability of } \\
\text { Being in Upstate }\end{array}$ & $\begin{array}{c}\text { Probability of } \\
\text { Being in } \\
\text { Downstate }\end{array}$ & $\begin{array}{c}\text { Mean Absolute Error } \\
(\%)\end{array}$ & $\begin{array}{c}\text { Difference in } \\
\text { Mean Absolute } \\
\text { Error (\%) }\end{array}$ & $\begin{array}{l}\text { SETAR } \\
\text { better? }\end{array}$ \\
\hline \multirow{2}{*}{ Argentina } & LAR AR (1) & & & 50.84 & \multirow{2}{*}{$-45 \cdot 5 \%$} & \multirow{2}{*}{ Yes } \\
\hline & SETAR & $23.5 \%$ & $76.5 \%$ & 27.72 & & \\
\hline \multirow{2}{*}{ China } & LAR ARIMA $(1,1,1)$ & & & 27.41 & \multirow{2}{*}{$43.4 \%$} & \multirow{2}{*}{ No } \\
\hline & SETAR & $15.2 \%$ & & 39.32 & & \\
\hline \multirow{2}{*}{ Indonesia } & LAR ARIMA $(1,1,0)$ & & & 46.08 & \multirow{2}{*}{$-37.4 \%$} & \multirow{2}{*}{ Yes } \\
\hline & SETAR & $14.9 \%$ & $85.1 \%$ & 28.85 & & \\
\hline \multirow{2}{*}{ Malaysia } & LAR ARIMA $(1,1,1)$ & & & 16.54 & \multirow{2}{*}{$7.9 \%$} & \multirow{2}{*}{ No } \\
\hline & SETAR & $15.3 \%$ & $84.7 \%$ & 17.85 & & \\
\hline \multirow{2}{*}{ Philippines } & LAR ARIMA $(1,1,0)$ & & & $47 \cdot 38$ & \multirow{2}{*}{$-51.5 \%$} & \multirow{2}{*}{ Yes } \\
\hline & SETAR & $16.7 \%$ & $83.3 \%$ & 22.99 & & \\
\hline \multirow{2}{*}{ Singapore } & LAR ARIMA $(1,1,0)$ & & & 39.19 & \multirow{2}{*}{$-48.2 \%$} & \multirow{2}{*}{ Yes } \\
\hline & SETAR & $48.3 \%$ & $51.7 \%$ & 20.31 & & \\
\hline \multirow{2}{*}{ Sri Lanka } & LAR ARIMA $(1,1,0)$ & & & 26.53 & \multirow{2}{*}{$-57.9 \%$} & \multirow{2}{*}{ Yes } \\
\hline & SETAR & $16.9 \%$ & $83.1 \%$ & 11.16 & & \\
\hline \multirow{2}{*}{ Taiwan } & LAR AR (1) & & & $15 \cdot 39$ & \multirow{2}{*}{$-29.2 \%$} & \multirow{2}{*}{ Yes } \\
\hline & SETAR & $58.8 \%$ & $41.2 \%$ & 10.89 & & \\
\hline Thailand & LAR ARIMA $(1,1,0)$ & & & 19.92 & \multirow[t]{2}{*}{$-6.9 \%$} & \multirow[t]{2}{*}{ Yes } \\
\hline \multirow[b]{2}{*}{ Turkey } & $\begin{array}{l}\text { SETAR } \\
\text { LAR AR(6)I(1)MA(6) }\end{array}$ & $15 \cdot 3 \%$ & $84.7 \%$ & 18.54 & & \\
\hline & $\begin{array}{l}\text { LAK AK(O) I(1)MA(O) } \\
\text { SETAR }\end{array}$ & $58.0 \%$ & $41 . \%$ & $44 \cdot 36$ & $-23.7 \%$ & Yes \\
\hline \multirow{3}{*}{ Venezuela } & LAR AR (1) & 50.970 & $41.1 \%$ & $\begin{array}{l}33.00 \\
17.64\end{array}$ & \multirow[b]{2}{*}{$5.6 \%$} & \multirow[b]{2}{*}{ No } \\
\hline & SETAR & $15.2 \%$ & $84.8 \%$ & 18.61 & & \\
\hline & & & & $\begin{array}{l}\text { Average for 'Yes' cases } \\
\text { Median for 'Yes' cases }\end{array}$ & $\begin{array}{l}-37.5 \% \\
-41.4 \%\end{array}$ & \\
\hline
\end{tabular}

Panel B: Developed Markets

\begin{tabular}{|c|c|c|c|c|c|c|}
\hline Market & Model & $\begin{array}{c}\text { Probability of } \\
\text { Being in Upstate }\end{array}$ & $\begin{array}{c}\text { Probability of } \\
\text { Being in } \\
\text { Downstate } \\
\end{array}$ & $\begin{array}{c}\text { Mean Absolute Error } \\
(\%)\end{array}$ & $\begin{array}{c}\text { Difference in } \\
\text { Mean Absolute } \\
\text { Error (\%) } \\
\end{array}$ & $\begin{array}{l}\text { SETAR } \\
\text { better? }\end{array}$ \\
\hline Finland & $\begin{array}{l}\text { LAR ARIMA }(0,1,1) \\
\text { SETAR }\end{array}$ & $15.7 \%$ & $84.3 \%$ & $\begin{array}{l}30.04 \\
22.62\end{array}$ & $-24.7 \%$ & Yes \\
\hline Japan & $\begin{array}{l}\text { LAR ARIMA }(1,1,0) \\
\text { SETAR }\end{array}$ & $20.0 \%$ & $80.0 \%$ & $\begin{array}{l}17 \cdot 94 \\
15 \cdot 39\end{array}$ & $-14.2 \%$ & Yes \\
\hline Netherlands & $\begin{array}{l}\text { LAR ARIMA }(1,1,1) \\
\text { SETAR }\end{array}$ & $17.6 \%$ & $82.4 \%$ & $\begin{array}{l}25.24 \\
21.63\end{array}$ & $-14.3 \%$ & Yes \\
\hline New Zealand & $\begin{array}{l}\text { LAR ARIMA }(3,1,3) \\
\text { SETAR }\end{array}$ & $57.1 \%$ & $42.9 \%$ & $\begin{array}{l}24 \cdot 5^{2} \\
23 \cdot 30\end{array}$ & $-5.0 \%$ & Yes \\
\hline Portugal & $\begin{array}{l}\text { LAR ARIMA }(1,1,0) \\
\text { SETAR }\end{array}$ & $84.4 \%$ & $15.6 \%$ & $\begin{array}{l}24.64 \\
33.61\end{array}$ & $36.4 \%$ & No \\
\hline US & $\begin{array}{l}\text { LAR ARIMA }(1,1,0) \\
\text { SETAR }\end{array}$ & $14.9 \%$ & $85.1 \%$ & $\begin{array}{r}13.34 \\
14.65 \\
\end{array}$ & $9.9 \%$ & No \\
\hline & & & & $\begin{array}{l}\text { Average for 'Yes' cases } \\
\text { Median for 'Yes' cases }\end{array}$ & $\begin{array}{l}-14.5 \% \\
-14.3 \% \\
\end{array}$ & \\
\hline
\end{tabular}

We use the Mean Absolute Percentage Error (MAPE) to measure predictive accuracy. MAPE is the average of the absolute percentage errors (differences) between the forecasts and the actual, observed values; the smaller its value, the larger the 
predictive power of a model. Finally, we calculate the difference in the mean absolute error-namely, the improvement in accuracy of one technique over the other.

Exhibit 2 demonstrates that SETAR comes out in better shape in most markets. In the emerging-market category, it produces more accurate forecasts in 8 out of 11 cases (or $73 \%$ of the sample). Where SETAR's forecast is superior, it reduces absolute forecast error by close to $38 \%$-a strikingly large gain in accuracy. Across developed markets, SETAR is more accurate in 4 out of 6 cases (or $67 \%$ of the sample); where SETAR's forecast is superior, it reduces absolute forecast error by close to $15 \%-$ a smaller yet material improvement.

\section{The Future of Regime-Switching Models}

Investors should recognize that both fair and stormy weather will shape the longterm value of their investments. Regime-switching modeling tackles the issue head-on by assuming that not all asset markets are mean-reverting systems punctuated by rare crashes, but can instead display a regime-switching behavior that is partially predictable. 
This paper-the first ever to apply SETAR to a large number of developed and emerging stock markets-hints to the potential usefulness of regime-switching (RS) models. Firstly, RS can be useful in asset allocation and the definition of trading rules. Portfolios that were constructed under the assumption of a single regime may turn out to be suboptimal if RS is present; taking RS into account will properly optimize the asset allocation procedure. For examples, see Bauer, Haerden, and Molenaar [2004], Ang and Bekaert [2004], and Kole, Koedijk, and Verbeek [2006].

RS models can also be applied when crafting long-range value scenarios. Pension fund managers and consultants customarily draw long-term models of returns by using RS techniques (Fabozzi, Focardi, and Kolm [2006]; for an application, see Mulvey [1996]). In corporate valuation, RS models could become instrumental in eradicating naïve scenario planning, the arbitrary use of three value scenarios (expected, optimistic and pessimistic) to which analysts attach whimsical values and probabilities. RS provides a refreshing change by which the number of scenarios, and their values and attached probabilities, are objectively derived from actual history; see Pereiro [2009] for an example.

Last, we expect the use of RS models to grow in the long-term forecasting of prices, returns, earnings and dividends-the daily bread of research analysts. As we have shown in this article, univariate nonlinear techniques have the true potential to materially improve the accuracy of long-term financial forecasts. 


\section{ENDNOTES}

${ }^{1}$ LAR models include the AR, MA, ARMA, and ARIMA formulations; for a technical review, see Mills [1999].

${ }^{2}$ For a general review of regime-switching models, see Priestley [1980, 1988], Tong [1990], Granger [1992], and Granger and Terasvirta [1993]. For a SETAR-focused review, see De Gooijer and Kumar [1992]. SETAR has not been popular in financial economics due to programming complexity: in contrast to AR models, there is no readymade, off-the-shelf estimation software for SETAR; as a result, researchers must perform their own modeling by using a standard statistical package, like GAUSS. Recently, however, Baragona and Cucina (2009) have made public a ready-made SETAR estimator that runs under a Microsoft Windows environment; advances like this will make SETAR modeling accessible to a larger public.

3 We compute thresholds directly on stock price index, and not on the first difference of its $\log$, for it is not readily apparent that taking logs will improve forecasting precision. Log is an instantaneous nonlinear transformation which, when applied to the optimal forecast of a variable, may not result in the optimal forecast of the transformed variable. In particular, if optimal forecasts of the logs are available, transforming them into forecasts for the original variable by applying the exponential function is in general not optimal (Granger and Newbold [1976]). In fact, research by Luktepohl and Xu's [2009] demonstrates that most long forecasts of stock market indexes are much more accurate 
when one works with the indexes themselves rather than with their logs; thus our choice. As for taking first differences, such is a linear transformation which has no effect in our results: differentiation alters neither the means or coefficients of Equation (1) nor the value of the threshold.

4 As Equation (1) shows, the threshold value is subsumed within the 'down' regime. Since $X_{t}=\alpha_{1} X_{t-1}+\delta I\left(X_{t-1} \leq r\right) X_{t-1}+u_{t}$, what we test is the null hypothesis of linearity (i.e., no threshold and no distinct regimes): $H o: \delta=0$. The statistic proposed to test the presence of a two-regime model is the maximum (called supremum) of the square of the $t$-statistic for $\delta=0$ under the null hypothesis that the underlying stochastic process has a unit root. The threshold value is given by the value of $r$ where the supremum is reached [Chan, 1993].

5 The forecasting equation is: $\mathrm{E}\left(\mathrm{X}_{\mathrm{t}+1}\right)=\mu_{1} \mathrm{E}\left[\mathrm{I}\left(\mathrm{X}_{\mathrm{t}}>\mathrm{r}\right)\right]+\mu_{2} \mathrm{E}\left[\mathrm{I}\left(\mathrm{X}_{\mathrm{t}} \leq \mathrm{r}\right)\right]+\alpha_{1} \mathrm{E}\left[\mathrm{I}\left(\mathrm{X}_{\mathrm{t}}>\mathrm{r}\right)\right] \mathrm{X}_{\mathrm{t}}$ $+\alpha_{2} E\left[I\left(X_{t} \leq r\right)\right] X_{t}+u_{t}$, where $E\left(X_{t+1}\right)$ is the forecast of the index value, $E\left[I\left(X_{t}>r\right)\right]$ is the probability of the index being in the upstate (or upper) regime, and $E\left[I\left(X_{t} \leq r\right)\right]$ is the probability of the index being at the threshold or in the lower regime. Probabilities are calculated as the limit of long-run relative frequency; upstate probability, for example, is the number of months the market index remains above the threshold divided by the total number of months available in the series.

\section{REFERENCES}


Ang, A., and G. Bekaert. "How Regimes Affect Asset Allocation." Financial Analysts Journal, Vol. 6o, No. 2 (2004), pp. 86-99.

Baragona, R., and D. Cucina. "Genetic Search for Threshold Parameters in Time Series Threshold Models: Algorithms and Computer Programs.” DSPSA, Sapienza University of Rome, ITA, 2009.

Bauer, R., R. Haerden, and R. Molenaar. “Asset Allocation in Stable and Unstable Times.” Journal of Investing, Vol. 13, No. 3 (2004), pp. 72-80.

Chan, K.S. "Consistency and Limiting Distribution of the Least Squares Estimator of a Threshold Autoregressive Model.” The Annals of Statistics, Vol. 21, No. 1 (1993), pp. 520-533.

De Gooijer, J.G., and K. Kumar. "Some Recent Developments in Non-Linear Time Series Modelling,Testing and Forecasting.” International Journal of Forecasting, Vol. 8, No. 2 (1992), pp. 135-156.

Fabozzi, F.J., Focardi, S.M., and P.N. Kolm. "A Simple Framework for Time Diversification.” Journal of Investing, Vol. 15, No. 3 (2006), pp. 8-17.

Goetzmann, W. N., and P. Jorion. "Re-Emerging Markets", Journal of Financial and Quantitative Analysis, Vol. 34, No. 1 (1999), pp. 1 - 31. 
González-Rozada, M., and J. Gonzalo. "Threshold Unit Root Models.” Working Paper 97-50 (21), Statistics and Econometrics, Universidad Carlos Tercero (Madrid), 1997.

Granger, C.W.J. "Forecasting Stock Market Prices: Lessons for Forecasters." International Journal of Forecasting, Vol. 8, No. 1 (1992), pp. 3-13.

Granger, C.W., and P. Newbold. “Forecasting Transformed Series.” Journal of the Royal Statistical Society, Vol. B 38, No. 2 (1976), pp. 189-203.

Granger, C.W.J., and T. Terasvirta. Modeling Nonlinear Economic Relationships, Oxford:Oxford University Press, 1993.

Kole, E., Koedijk, K., and M. Verbeek. "Portfolio Implications of Systemic Crises." Journal of Banking and Finance, Vol. 30, No. 8 (2006), pp. 2347-2369.

Lutkepohl, H., and F. Zu. "The Role of the Log Transformation in Forecasting Economic Variables.” CESifo Working Paper 2591, 2009.

Mills, T.C. The Econometric Modeling of Financial Time Series, Cambridge:Cambridge University Press, 1999.

Mulvey, J.M. "Generating Scenarios for the Towers Perrin Investment System." Interfaces, Vol. 26, No. 2 (1996), pp. 1-15. 
Pereiro, L.E. "Valuing Acquisitions in Emerging Markets: An Extreme Scenario Framing Approach.” Revista de Instituciones, Ideas y Mercados, Vol. 50 (2009), pp. 8-36.

Priestley, M.B. "State-Dependent Models: A General Approach to Non-Linear Time Series Analysis.” Journal of Time Series Analysis, Vol. 1, No. 1 (1980), pp. 47-71.

Priestley, M.B. Non-Linear and Non-Stationary Time Series Analysis, New York:Academic Press, 1988.

Tong, H. "Threshold Models in Non-Linear Time Series Analysis", Lectures Notes in Statistics, Vol. 21, Springer and Verlag, 1983.

Tong, H. "Non-Linear Time Series: A Dynamical System Approach." Oxford:Oxford University Press, 1990. 